\title{
Análise probabilística de parâmetros de qualidade da água para suporte ao processo de enquadramento de cursos d'água
}

\author{
Probabilistic water quality parameters analysis for supporting \\ Brazilian watercourses use classes definition processes
}

\author{
Brunna Oliveira Guimarães ${ }^{1}$, José Antonio Tosta dos Reis², \\ Antônio Sérgio Ferreira Mendonça ${ }^{3}$, Lucien Akabassi ${ }^{4}$
}

\begin{abstract}
RESUMO
O presente trabalho teve como objetivo geral estudar o emprego de curvas de probabilidade da qualidade da água como subsídio para o enquadramento legal dos corpos dágua. Para a avaliação da utilização das referidas curvas foram reunidas informações sobrequalidade daágua do Rio Jucu, principal manancial de abastecimento da Região Metropolitana da Grande Vitória, Espírito Santo. A partir da função de distribuição acumulada, foram construídas curvas de probabilidade de ocorrência para diferentes parâmetros físicos, químicos e bacteriológicos de qualidade de água, e avaliadas frequências de incompatibilidade com padrões estabelecidos pela Resolução CONAMA no 357/2005 para diferentes classes de uso. A avaliação de incompatibilidade considerou duas perspectivas: (1) enquadramento único para o curso d’água, perspectiva na qual as curvas de probabilidade foram construídas com a reunião de todos os registros de qualidade dos diferentes pontos de monitoramento; e (2) enquadramento diferenciado ao longo do curso dágua. Avaliou-se, adicionalmente, a influência da sazonalidade do regime hidrológico sobre as respostas oferecidas pelas curvas de probabilidade. Os resultados indicaram que os parâmetros fósforo total e coliformes termotolerantes apresentaram elevados percentuais de incompatibilidade, independentemente da classe de uso, da perspectiva de enquadramento (único ou diferenciado ao longo do rio) e do período do ano hidrológico (seco ou úmido). A avaliação sazonal demonstrou que apenas o parâmetro de turbidez, quando considerada a perspectiva de enquadramento na classe 1, apresentou diferença entre as frequências de incompatibilidade observadas para os períodos seco e úmido do ano hidrológico.
\end{abstract}

Palavras-chave: enquadramento; curva de probabilidade; qualidade de água.

\begin{abstract}
The present work aims to study the use of water quality probability curves for technical support of legal watercourse reaches water uses class definition. For the evaluation of the use of such curves, we used data from the Jucu River water quality. This is the main water source of the metropolitan region of Vitória, Espírito Santo, Brazil. From the accumulated distribution function, different physical, chemical and bacteriological water quality parameters probability curves were fitted to the monitoring data in order to evaluate frequencies of incompatibility with established legal standards corresponding to different Brazilian National Council CONAMA 357/2005 Resolution watercourse use classes. The incompatibility evaluation considered two different conditions: (1) unique, by aggregating all water quality parameters values for all different monitoring points; and (2) different water use classes along the Jucu River. Additionally, the influence of the hydrological regime seasonality on the probability curves was evaluated. The results indicated that total phosphorus and coliforms parameters presented high incompatibility frequencies, regardless of water use class (unique or different along the river) and season (dry or wet). The seasonal assessment showed that only the turbidity parameter presented significant differences among incompatibility frequencies, considering wet and dry periods of the hydrological year, and only for the CONAMA Resolution water use class 1.
\end{abstract}

Keywords: water use classification; probability curve; water quality.Arci blaboriosa voloriorat adipsan ihilles unt aditat earum rat.

\footnotetext{
$\square$

'Mestre em Engenharia de Saúde Pública e Desenvolvimento Sustentável pela Universidade Federal do Espírito Santo (UFES). Professora das Faculdades Integradas EspíritoSantenses (FAESA) - Vitória (ES), Brasil.

${ }^{2}$ Doutor em Hidráulica e Saneamento pela Escola de Engenharia de São Carlos da Universidade de São Paulo (USP). Professor do Departamento de Engenharia Ambiental da UFES - Vitória (ES), Brasil.

${ }^{3}$ Doutor em Engenharia de Recursos Hídricos pela Colorado State University. Professor do Departamento de Engenharia Ambiental da UFES - Vitória (ES), Brasil.

${ }^{4}$ Doutor em Hidráulica e Saneamento pela Escola de Engenharia de São Carlos da USP. Professor da Coordenadoria de Saneamento Ambiental do Instituto Federal do Espírito Santo (IFES) - Vitória (ES), Brasil.

Endereço para correspondência: Brunna Oliveira Guimarães - Rua Doutor Antônio Basílio, 750, apartamento 203A, Edifício laponã - Bairro Jardim da Penha - $29060-390$ -

Vitória (ES) Brasil - E-mail: brunnaoguimaraes@gmail.com

Recebido: 25/11/14 - Aceito: 04/04/16 - Reg. ABS: 143190
} 


\section{INTRODUÇÃO}

De acordo com a Política Nacional de Recursos Hídricos (PNRH), editada por meio da Lei $\mathrm{n}^{\circ} 9.433$, de 8 de janeiro de 1997 , o enquadramento de corpos d'água em classes, segundo os usos preponderantes da água, tem como principais objetivos garantir às águas qualidade compatível com os usos mais exigentes a que forem destinadas e diminuir os custos de combate à poluição das águas, mediante ações preventivas permanentes (BRASIL, 1997). Sendo um instrumento de gestão de recursos hídricos que objetiva estabelecer o nível de qualidade (classe) a ser alcançado e/ou mantido em um segmento de corpo d'água ao longo do tempo, o enquadramento não se baseia no estado atual de qualidade, mas nos níveis de qualidade que um corpo d'água deveria possuir para atender às necessidades definidas pela sociedade (MARINATO et al., 2008).

O enquadramento ganha relevância quando se busca estabelecer um sistema de vigilância sobre os níveis de qualidade da água de mananciais. Além de permitir a ligação entre a gestão da qualidade e quantidade da água, o enquadramento impõe ou fortalece a relação entre a gestão de recursos hídricos e do meio ambiente.

A tendência de estabelecimento de sistemas de gestão dos corpos d'água a partir do seu agrupamento por classes de uso, características fisiográficas ou ecológicas tem se estabelecido em diferentes países (ACHLEITNER et al., 2005; CHEN; LIU; LEU, 2006; CARONE et al., 2009).

No Brasil, muitos trabalhos têm buscado estabelecer metodologias que ofereçam suporte ao enquadramento de corpos d'água superficiais. Constituem exemplos desse esforço os trabalhos de Leewestein (2000), Silva e Ribeiro (2006), Cunha e Calijuri (2010), Brites (2010), Binoto (2012), Garcia et al. (2012), Cunha et al. (2013) e Calmon et al. (2014).

Dentre os referidos trabalhos, a metodologia empregada por Cunha e Calijuri (2010) teve por objetivo oferecer suporte ao enquadramento de corpos d’água a partir da análise probabilística de ocorrência de incompatibilidades entre a qualidade da água e os diferentes padrões que conformam o enquadramento legal dos corpos d'água brasileiros. Segundo os referidos autores, por representarem um nível interessante de condensação de informações, as curvas probabilísticas podem orientar o processo decisório, facilitar o gerenciamento integrado da água em uma bacia hidrográfica e, adicionalmente, favorecer a divulgação dos resultados para a sociedade.

Buscando avaliar as alternativas de enquadramento para o Rio Piraquera-Açu, curso d'água de domínio do estado de São Paulo que integra a Unidade de Gerenciamento de Recursos Hídricos Ribeira do Iguape - Litoral Sul, Cunha e Calijuri (2010) conduziram monitoramento da qualidade da água do referido curso d'água ao longo do ano de 2007, acompanhando a variação espacial e temporal dos parâmetros oxigênio dissolvido (OD), turbidez, fósforo total, nitrogênio amoniacal, nitrito, nitrato e clorofila-a. A partir dos resultados obtidos foram estimadas as probabilidades de ocorrência de incompatibilidades entre as concentrações observadas no rio e os respectivos limites, superiores ou inferiores, descritos na Resolução CONAMA n 357/2005 para corpos d'água classe 2 .

O trabalho proposto por Cunha e Calijuri (2010) assumiu como perspectiva o enquadramento único para toda a extensão do Rio Piraquera-Açu, agrupando registros de qualidade de água apropriados em diferentes pontos de monitoramento estabelecidos ao longo do rio. No entanto, sinalizou como possíveis aprimoramentos da metodologia, a análise dos dos registros de qualidade de água por ponto de monitoramento e a incorporação da avaliação sazonal.

Nesse contexto, o principal objetivo deste trabalho é conduzir a análise probabilística de ocorrência de incompatibilidades entre a qualidade da água e os padrões ambientais estabelecidos pela CONAMA $n^{\circ} 357 / 2005$ como suporte para o enquadramento do Rio Jucu, principal manancial de abastecimento da Região Metropolitana da Grande Vitória, Espírito Santo. Num primeiro momento, a perspectiva de enquadramento foi avaliada a partir da análise agrupada dos registros de qualidade de água, reproduzindo-se a abordagem de Cunha e Calijuri (2010), por meio da qual seria definido enquadramento único para todo o rio. Na sequência, diferentemente da proposta original dos referidos autores, avaliou-se a possibilidade de enquadramento diferenciado ao longo da extensão do curso d'água, conduzindo-se a análise individualizada dos registros de qualidade de água por ponto de monitoramento. Adicionalmente, foi avaliada a influência da sazonalidade hidrológica sobre os resultados obtidos a partir do emprego da análise probabilística da ocorrência de incompatibilidades.

\section{Área de estudo}

A bacia do Rio Jucu é a principal contribuinte para o abastecimento da Região Metropolitana da Grande Vitória e, numa área de drenagem de aproximadamente $2.200 \mathrm{~km}^{2}$, abrange os municípios de Domingos Martins e Marechal Floriano e parte dos municípios de Viana, Vila Velha Cariacica e Guarapari, todos no estado do Espírito Santo.

O Rio Jucu apresenta suas nascentes situadas na região serrana do estado, em altitudes de até $1.800 \mathrm{~m}$ acima do nível médio do mar, com foz localizada no balneário da Barra do Jucu, no município de Vila Velha, junto ao Oceano Atlântico. Na região serrana o Rio Jucu apresenta dois braços: o Braço Sul, mais curto, com 67,43 km de extensão e o Braço Norte, mais extenso, com 126,56 km. Após a confluência de seus braços, o Rio Jucu ainda percorre $42,94 \mathrm{~km}$ até atingir sua foz, totalizando $169,5 \mathrm{~km}$ de extensão. A vazão média na foz é de $35 \mathrm{~m}^{3} \cdot \mathrm{s}^{-1}$. Entre seus principais afluentes estão os rios Barcelos, Ponte, Melgaço, Chapéu, Galo, Fundo, Jacarandá, Calçado e Claro, os quais abastecem, com o Rio Jucu, os terrenos da bacia utilizados, principalmente, para os cultivos de café, legumes e hortaliças, para o desenvolvimento de atividades ligadas ao turismo, para a proteção e conservação dos 
recursos naturais em unidades de conservação e para desenvolvimento e expansão de aglomerados urbanos (GUIMARÃES, 2013).

As localizações das estações de monitoramento da qualidade de água, em operação ao longo do Rio Jucu, são descritas no Quadro 1.

\section{METODOLOGIA}

\section{Registros de qualidade de água}

Os registros de qualidade de água empregados na condução do presente trabalho, a partir dos quais se estabeleceu a análise probabilística da incompatibilidade entre a qualidade da água e os padrões ambientais, foram disponibilizados pelo Laboratório de Análises e Parâmetros Ambientais Moacir Carvalheira de Mendonça, laboratório vinculado ao Instituto Estadual de Meio Ambiente e Recursos Hídricos (IEMA).

Considerando-se a perspectiva de discussões associadas ao enquadramento de corpos d'água em classes de uso, foram considerados, dentre os parâmetros monitorados pelo IEMA, aqueles para os quais existem padrões de qualidade estabelecidos por meio da Resolução CONAMA n 357/2005. Dessa forma, foram construídas curvas de probabilidade de ocorrência para os parâmetros $\mathrm{pH}, \mathrm{OD}$, turbidez, sólidos totais, demanda bioquímica de oxigênio (DBO), fósforo total e coliformes termotolerantes.

\section{Registros pluviométricos}

A distribuição espacial e temporal das precipitações e as intensidades de eventos individuais de precipitação constituem características que afetam direta ou indiretamente a qualidade dos corpos d'água.

A fim de analisar os efeitos da sazonalidade sobre as perspectivas de enquadramento, foram identificados os períodos (semestres) seco e úmido de um ano hidrológico típico, ano estabelecido a partir da média de longo período dos totais mensais precipitados. Nessa etapa do trabalho foram apropriadas as médias dos totais mensais precipitados para períodos de seis meses consecutivos, a partir das quais foram

Quadro 1 - Localização dos pontos de monitoramento da qualidade da água do Rio Jucu.

\begin{tabular}{|c|c|c|c|}
\hline \multirow{2}{*}{$\begin{array}{l}\text { Ponto de } \\
\text { coleta }\end{array}$} & \multirow{2}{*}{ Curso d’água } & \multicolumn{2}{|c|}{$\begin{array}{c}\text { Coordenadas } \\
\text { geográficas (UTM) }\end{array}$} \\
\hline & & Latitude & Longitude \\
\hline Ponto 1 & Rio Jucu - Braço Norte & $7752648 N$ & 327021E \\
\hline Ponto 2 & Rio Jucu - Braço Sul & $7742071 \mathrm{~N}$ & 32452OE \\
\hline Ponto 3 & Rio Jucu - Braço Sul & $7742551 \mathrm{~N}$ & 325603E \\
\hline Ponto 4 & Rio Jucu - Braço Sul & $7744465 N$ & 335392E \\
\hline Ponto 5 & Rio Jucu - Braço Norte & $7746163 \mathrm{~N}$ & $337201 E$ \\
\hline Ponto 6 & Rio Jucu - Calha principal & $7740027 \mathrm{~N}$ & 347799E \\
\hline
\end{tabular}

UTM: Universal Transversa de Mercator. definidos os semestres seco e úmido do ano hidrológico. Para essa tarefa foram considerados os registros disponíveis entre os anos de 1960 e 2011 nas estações pluviométricas de Córrego do Galo e Fazenda Jucuruaba, instaladas e em operação na bacia hidrográfica do Rio Jucu.

Os registros diários de precipitação foram obtidos a partir do sítio da Agência Nacional de Águas (ANA). Para a manipulação dos registros pluviométricos foi empregado o programa computacional Hidro (ANA, 2002), programa de domínio público disponibilizado pela ANA.

\section{Curvas de probabilidade}

As curvas de probabilidade, a partir das quais foram avaliadas as frequências de incompatibilidades entre a qualidade da água e os padrões de enquadramento legal, foram construídas de acordo com procedimento apresentado por Cunha e Calijuri (2010).

Para a construção das referidas curvas foi empregada a função de distribuição acumulada, função detalhadamente apresentada e discutida por Spiegel (1985), Levine et al. (2005) e Soong (1986).

A função de distribuição acumulada de probabilidades indica com que frequência uma variável aleatória $\mathrm{X}$ é menor ou igual ao argumento $\mathrm{x}$. No presente estudo a variável aleatória X representa as concentrações dos diferentes parâmetros de qualidade da água sistematicamente monitorados pelo IEMA. Os padrões de qualidade ambiental estabelecidos pela Resolução CONAMA nº 357/2005, por sua vez, definem os valores do argumento $\mathrm{x}$. O valor da função de distribuição acumulada [F(x)], para cada número real x, é dado de acordo com a Equação 1.

$\mathrm{F}(\mathrm{x})=\mathrm{P}(\mathrm{X} \leq \mathrm{x})$

A probabilidade de interesse nesta pesquisa refere-se ao valor de $\mathrm{F}(\mathrm{x})$ para $\mathrm{x}$ igual ao padrão de qualidade ambiental. Essa frequência representa, em termos práticos, a probabilidade de incompatibilidade da qualidade da água com o enquadramento legal. Para o parâmetro $\mathrm{OD}$ interessa a frequência de não excedência. Para o parâmetro $\mathrm{pH}$, a soma das frequências com que os registros de monitoramento apresentaram-se inferiores a 6,0 ou superiores a 9,0 (o padrão ambiental impõe $6,0<\mathrm{pH}<9,0$ para águas doces classes 1,2 e 3). Para os demais parâmetros de qualidade (DBO, turbidez, sólidos totais, fósforo total e coliformes termotolerantes) são relevantes as frequências de excedência dos padrões de qualidade ambiental.

Para avaliação das porcentagens de ocorrência de incompatibilidade entre os valores observados em campo e os padrões de qualidade ambiental, foram considerados, neste trabalho, os padrões estabelecidos para rios classes 1, 2 ou 3. Essa abordagem, considerando diferentes classes, tem por objetivo oferecer subsídios para a implementação do enquadramento do Rio Jucu, tendo em vista o fato de que os corpos d'água de domínio do estado do Espírito Santo não passaram pelo processo de enquadramento legal. 
A avaliação da frequência de não atendimento aos padrões de enquadramento legal foi conduzida para as seguintes situações:

- por parâmetro de qualidade de água nos pontos de monitoramento;

- por parâmetro de qualidade de água, analisando-se conjuntamente os registros de qualidade de água obtidos a partir dos diferentes pontos de monitoramento do Rio Jucu, abordagem que reproduz o procedimento empregado por Cunha e Calijuri (2010) para o Rio Pariquera-Açu;

- por parâmetro de qualidade de água, em função dos períodos seco e úmido do ano hidrológico, agrupando-se todos os registros de qualidade disponíveis para o Rio Jucu.

\section{RESULTADOS E DISCUSSÃO}

\section{Análise individualizada dos pontos de monitoramento}

Para a avaliação da variação espacial da qualidade da água foram construídas curvas de incompatibilidade por ponto de amostragem e parâmetro de qualidade de água analisado. Os resultados obtidos nessa etapa do trabalho estão reunidos na Tabela 1. A título de exemplo, curvas de probabilidade de ocorrência dos parâmetros turbidez e coliformes termotolerantes, referentes ao primeiro ponto de monitoramento de qualidade de água do Rio Jucu, encontram-se representadas na Figura 1. As linhas verticais nos diferentes gráficos indicam os padrões de qualidade associados às diferentes classes de uso.

A análise por ponto de monitoramento parte da perspectiva de uma eventual definição de diferentes classes de enquadramento ao longo do curso d'água, com classes de uso mais restritivas nos trechos de montante dos rios. As informações reunidas na Tabela 1 não sugerem relevantes comprometimentos de qualidade de montante para jusante no Rio Jucu. Aos diferentes pontos de monitoramento instalados mais próximos das cabeceiras foram associados percentuais de incompatibilidade superiores aos localizados próximos da foz, independentemente do parâmetro de qualidade ou classe de uso considerada. A localização dos pontos de monitoramento, o aumento da capacidade de diluição (efeito decorrente do aporte de água por tributários de significativa vazão) ou os fenômenos que influenciam o processo de autodepuração podem explicar o padrão observado no corpo d'água analisado. Cabe observar que pontos instalados nos trechos de montante podem estar sob influência de interferências naturais ou antrópicas mais severas do que os pontos localizados à jusante.

O parâmetro $\mathrm{pH}$ é regulado por um mesmo padrão de qualidade em todas as classes de enquadramento (valores oscilando entre 6 e 9),

Tabela 1 - Porcentagem de não atendimento aos padrões de qualidade ambiental por ponto de monitoramento e por classe de qualidade de água associada ao Rio Jucu.

\begin{tabular}{|c|c|c|c|c|c|c|c|c|}
\hline \multirow{2}{*}{ Ponto de monitoramento } & \multirow{2}{*}{ Classe } & \multicolumn{7}{|c|}{ Parâmetro de qualidade (\%) } \\
\hline & & $\mathrm{pH}$ & OD & Turbidez & DBO & Sólidos totais & Fósforo total & Coliformes \\
\hline \multirow{2}{*}{ Ponto 1} & I & 5 & 5 & 20 & 18 & - & 72 & 100 \\
\hline & III & 5 & - & 5 & - & - & 31 & 39 \\
\hline \multirow{2}{*}{ Ponto2 } & I & 5 & - & 25 & 23 & 4 & 63 & 100 \\
\hline & III & 5 & - & 10 & 4 & 4 & 36 & 69 \\
\hline \multirow{3}{*}{ Ponto 3} & । & 9 & - & 25 & 20 & - & 86 & 100 \\
\hline & $\|$ & 9 & - & 10 & 4 & - & 63 & 100 \\
\hline & III & 9 & - & 10 & - & - & 45 & 100 \\
\hline \multirow{3}{*}{ Ponto 5} & 1 & 18 & - & 15 & 27 & - & 72 & 78 \\
\hline & $\|$ & 18 & - & 5 & 4 & - & 41 & 43 \\
\hline & III & 18 & - & 5 & - & - & 36 & 26 \\
\hline \multirow{3}{*}{ Ponto 6} & 1 & 5 & - & 21 & 14 & 5 & 85 & 86 \\
\hline & $\|$ & 5 & - & - & - & 5 & 62 & 67 \\
\hline & III & 5 & - & - & - & 5 & 43 & 48 \\
\hline
\end{tabular}

OD: oxigênio dissolvido; BDO: demanda bioquímica de oxigênio. 
o que explica uma mesma frequência de não atendimento para todas as classes de uso. Para o parâmetro de $\mathrm{pH}$, avaliou-se um percentual de incompatibilidade de, no máximo, 18\%. No Rio Jucu, a incompatibilidade com padrão ambiental esteve associada tanto a $\mathrm{pH}$ ácidos (14\%), quanto a $\mathrm{pH}$ básicos (4\%).

O Rio Jucu apresentou, invariavelmente, concentrações de OD superiores ao padrão ambiental referente às classes 2 e 3 . A incompatibilidade máxima associada ao padrão referente à classe 1 , por sua vez, não superou $5 \%$.

Considerando-se o grupo de parâmetros de qualidade de água reunido neste estudo, as eventuais definições de classes de enquadramento exigirão que, nos horizontes de planejamento estabelecidos por futuros planos de bacia (usualmente horizontes de médio ou longo prazo), sejam estabelecidos esforços para uma substancial redução das concentrações de fósforo e coliformes termotolerantes nos corpos d'água. As frequências máximas de não atendimento dos padrões associadas ao fósforo total variaram entre $31 \%$ (classe 3 ) e $86 \%$ (classe 1 ). Para o parâmetro coliformes termotolerantes, as incompatibilidades máximas oscilaram entre $26 \%$ (classe 3 ) e $100 \%$ (valor registrado em diferentes classes de uso e diferentes pontos de monitoramento). Convém registrar que a bacia estudada apresenta relevantes núcleos de atividades agropecuárias, além de vários aglomerados urbanos desprovidos de sistemas de tratamento de esgotos sanitários.

Os parâmetros sólidos totais, DBO e turbidez apresentaram valores máximos para os percentuais de incompatibilidade de 5, 25 e $27 \%$, respectivamente, todos eles associados aos padrões estabelecidos para a classe 1 .

\section{Análise agrupada dos pontos de monitoramento}

A análise agrupada dos pontos de monitoramento, proposição originalmente discutida por Cunha e Calijuri (2010), parte da perspectiva de adoção de um enquadramento único para toda a extensão do rio. Reunidos os registros de qualidade, foram apropriadas, por parâmetro de monitoramento, as porcentagens de incompatibilidade por possíveis classes de enquadramento indicadas na Tabela 2. A Figura 2 apresenta, como exemplos, as curvas de probabilidade associadas aos parâmetros turbidez e fósforo total.

A análise agrupada dos registros de qualidade de água atenua, quando da análise de frequência, os valores máximos de incompatibilidade entre registros de campo e padrões de qualidade ambiental. Nessa abordagem, os registros de qualidade de água dos diferentes pontos de monitoramento do curso d'água são reunidos numa única - e mais extensa - amostra, aspecto que associará, aos eventos extremos observados, uma menor frequência de ocorrência. Deve-se observar, portanto, que a análise agrupada refletirá condições médias de incompatibilidade ao longo do curso d’água.

Os parâmetros $\mathrm{pH}, \mathrm{OD}$ e sólidos totais apresentaram, independentemente da classe de uso, percentuais de incompatibilidade usualmente baixos, inferiores a $9 \%$, não limitando perspectivas de enquadramento entre as classes 1, 2 ou 3. Situação semelhante ocorre para os parâmetros turbidez e DBO, considerados eventuais enquadramentos nas classes 2 e 3, uma vez que as máximas incompatibilidades ocorreram com frequências máximas menores do que $10 \%$.

Tabela 2 - Porcentagens de não atendimento aos padrões de qualidade ambiental no Rio Jucu, agrupadas por classe possível de enquadramento.

\begin{tabular}{l|c|c|c|c|c|c|c}
\multirow{2}{*}{ Classe } & \multicolumn{7}{|c}{ Parâmetro de qualidade (\%) } \\
\cline { 2 - 8 } & pH & OD & Turbidez & DBO & $\begin{array}{c}\text { Sólidos } \\
\text { totais }\end{array}$ & $\begin{array}{c}\text { Fósforo } \\
\text { total }\end{array}$ & Coliformes \\
\hline Classe I & 8 & 2 & 20 & 23 & 2 & 80 & 94 \\
\hline Classe II & 8 & 1 & 6 & 6 & 2 & 50 & 76 \\
\hline Classe III & 8 & 1 & 6 & 1 & 2 & 40 & 56 \\
\hline
\end{tabular}

OD: oxigênio dissolvido; BDO: demanda bioquímica de oxigênio.

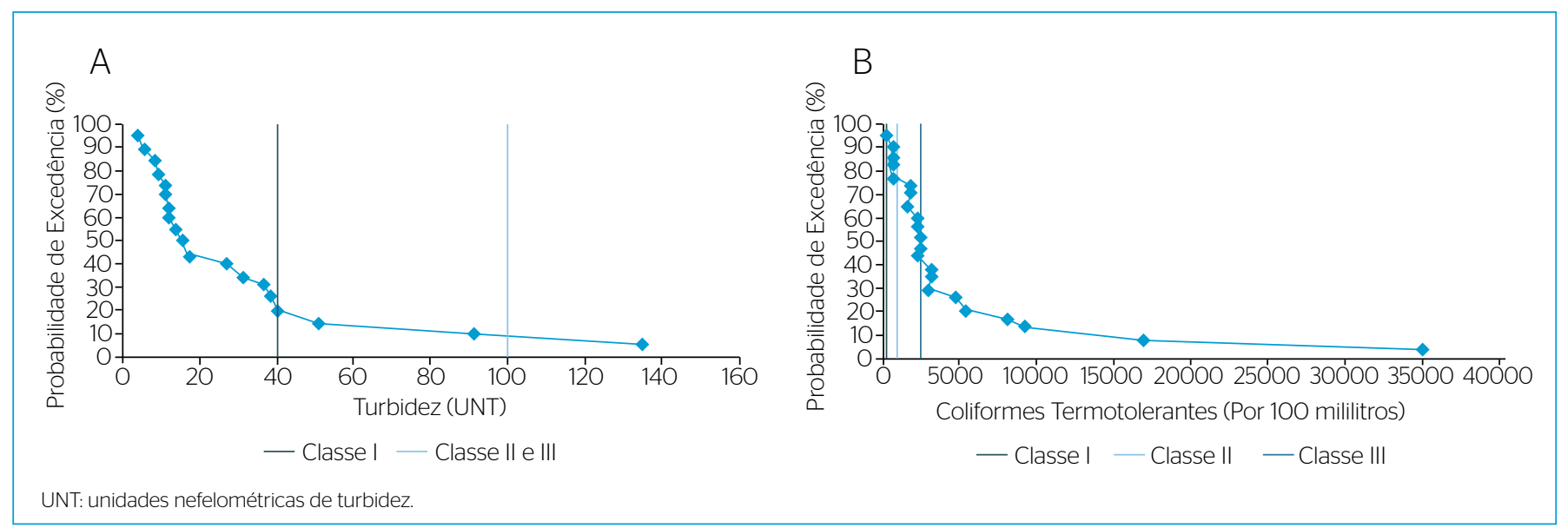

Figura 1 - Curva de probabilidade de excedência dos valores de turbidez (A) e das concentrações de coliformes termotolerantes (B) para o primeiro ponto de monitoramento da qualidade de água do Rio Jucu. 
Assim como observado quando da análise individualizada dos pontos de monitoramento, as concentrações de fósforo total e coliformes termotolerantes constituíram as maiores limitações à adequação aos padrões de qualidade ambiental. A partir das condições de qualidade registradas pelo monitoramento sistemático conduzido pelo órgão ambiental e dos padrões de qualidade associados aos referidos parâmetros, foram estimados percentuais de incompatibilidade que, para fósforo total, variaram entre $40 \%$ (considerando-se eventual enquadramento na classe 3) e $80 \%$ (quando da perspectiva de enquadramento na classe 1). Para os parâmetro coliformes termotolerantes, os percentuais de incompatibilidade apresentaram-se superiores a 50\%, independentemente da classe de uso, atingindo frequências de até $94 \%$, quando considerado o padrão de qualidade referente à classe 1 .

\section{Análise sazonal}

A partir da análise das médias móveis de totais mensais precipitados para períodos de seis meses consecutivos, definiu-se o intervalo entre os meses de maio e outubro como período seco do ano hidrológico e, de forma complementar, os meses de novembro a abril como período úmido.

Definidos os períodos seco e úmido do ano hidrológico, os dados de monitoramento da qualidade da água do Rio Jucu foram reagrupados, sendo construídas curvas de probabilidade por parâmetro de qualidade de água. Nessa etapa do trabalho, os registros de qualidade de água dos diferentes pontos de monitoramento foram agrupados, assumindo-se a possibilidade de enquadramento único para toda extensão do referido curso d'água. Os resultados obtidos nessa etapa do trabalho estão reunidos nas Tabelas 3 e 4 . As curvas de probabilidade que apresentaram as maiores diferenças ocorreram para os parâmetros turbidez, fósforo total e coliformes termotolerantes, que estão apresentadas na Figura 3.
Os parâmetros $\mathrm{pH}, \mathrm{OD}$, sólidos totais e $\mathrm{DBO}$ apresentaram percentuais de incompatibilidade inferiores a $25 \%$, quando considerados os padrões propostos para rios classe 1. Quando considerados os limites estabelecidos para rios classe 2 e 3 , a máxima frequência de não atendimento foi ligeiramente inferior a $10 \%$ (9\% para os parâmetros DBO e $\mathrm{pH}$ ) independentemente do período do ano hidrológico.

Os parâmetros fósforo total e coliformes termotolerantes apresentaram-se como limitantes para qualquer discussão sobre possíveis enquadramentos, uma vez que os percentuais de incompatibilidade foram elevados em relação aos padrões de qualquer classe de uso, independentemente do período do ano hidrológico. Para eventuais enquadramentos nas classes 1 e 2 , os percentuais de incompatibilidade referentes ao parâmetro variaram de $49 \%$ (fósforo total, período seco)

Tabela 3 - Porcentagem de não atendimento aos padrões de qualidade ambiental no Rio Jucu para o período seco do ano hidrológico.

\begin{tabular}{l|c|c|c|c|c|c|c}
\multirow{2}{*}{ Classe } & \multicolumn{7}{|c}{ Parâmetros de qualidade (\%) } \\
\cline { 2 - 9 } & pH & OD & Turbidez & DBO & $\begin{array}{c}\text { Sólidos } \\
\text { totais }\end{array}$ & $\begin{array}{c}\text { Fósforo } \\
\text { total }\end{array}$ & Coliformes \\
Classe I & 9 & - & 10 & 22 & 3 & 78 & 92 \\
\hline Classe II & 9 & - & 7 & 4 & 3 & 49 & 72 \\
\hline Classe III & 9 & - & 7 & - & 3 & 39 & 51 \\
\hline
\end{tabular}

OD: oxigênio dissolvido; BDO: demanda bioquímica de oxigênio.

Tabela 4 - Porcentagem de não atendimento aos padrões de qualidade ambiental no Rio Jucu para o período úmido do ano hidrológico.

\begin{tabular}{l|c|c|c|c|c|c|c}
\multirow{2}{*}{ Classe } & \multicolumn{7}{|c}{ Parâmetros de qualidade } \\
\cline { 2 - 9 } & pH & OD & Turbidez & DBO & $\begin{array}{c}\text { Sólidos } \\
\text { totais }\end{array}$ & $\begin{array}{c}\text { Fósforo } \\
\text { total }\end{array}$ & Coliformes \\
\hline Classe I & 8 & 4 & 32 & 24 & - & 83 & 96 \\
\hline Classe II & 8 & 2 & 4 & 9 & - & 50 & 79 \\
\hline Classe III & 8 & 2 & 4 & 2 & - & 36 & 62 \\
\hline
\end{tabular}

OD: oxigênio dissolvido; BDO: demanda bioquímica de oxigênio.

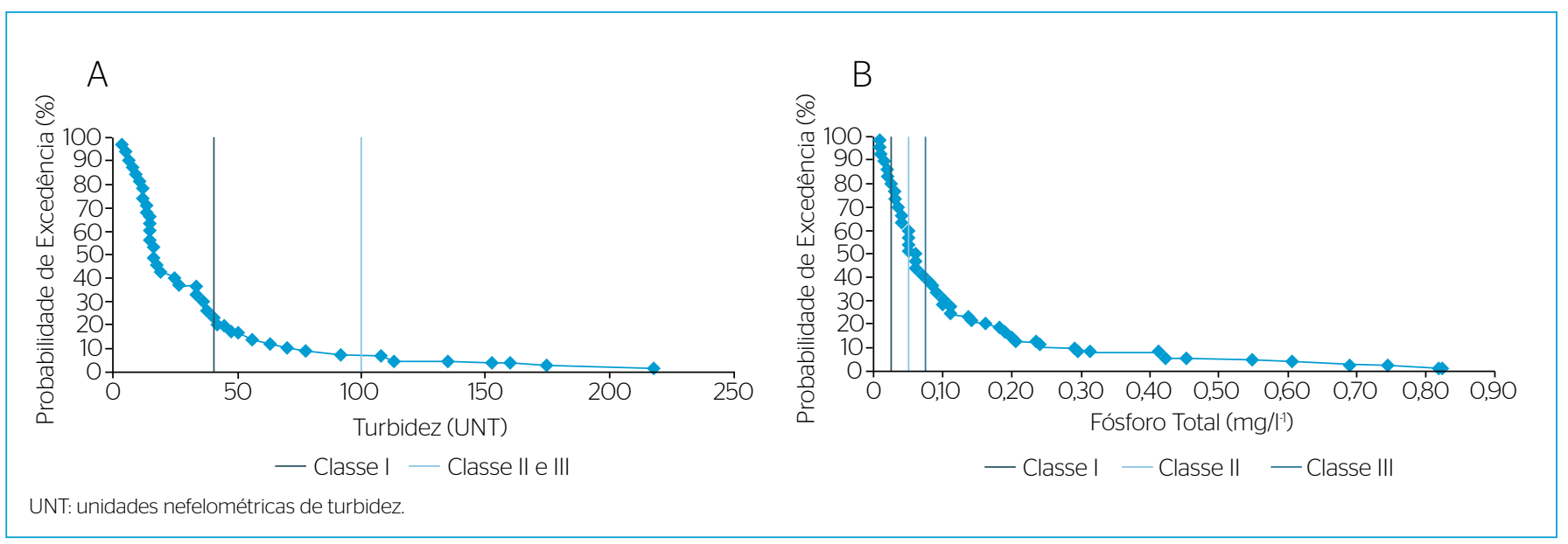

Figura 2 - Curva de probabilidade de excedência dos valores de turbidez (A) e concentrações de fósforo total (B). 
a 96\% (coliformes termotolerantes, período úmido). Valores mais baixos de percentuais de incompatibilidade foram associados à possibilidade de enquadramento na classe 3 , com valores variando de $36 \%$ (fósforo total, período úmido) a $62 \%$ (coliformes termotolerantes, período úmido).

O parâmetro turbidez apresentou frequência de incompatibilidade que variou de $10 \%$ (período seco) a $32 \%$ (período úmido), quando avaliada a perspectiva de enquadramento na classe 1. Essa variação é decorrente, no período úmido, do aumento dos níveis de sólidos em suspensão produzido pela maior incidência de chuvas.

É relevante observar que dentre os parâmetros de qualidade de água avaliados, excluindo-se a turbidez, não foram observadas variações significativas para os percentuais de incompatibilidade entre os períodos seco e úmido. Adicionalmente, deve-se ressaltar que o aumento

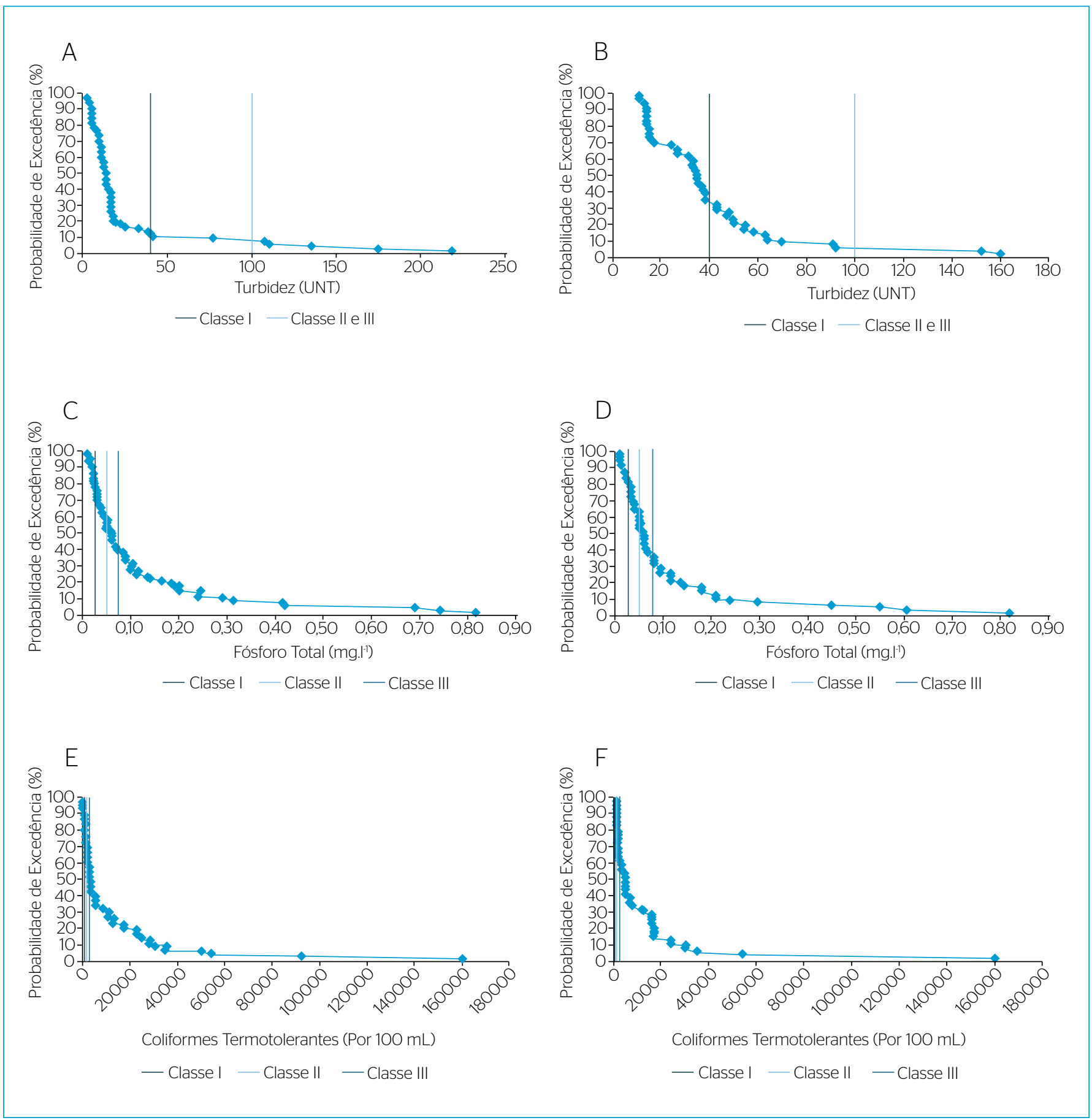

Figura 3 - Curva de probabilidade de excedência dos valores de turbidez no período seco (A) e úmido (B), concentrações de fósforo total no período seco (C) e úmido (D) e coliformes termotolerantes no período seco (E) e úmido (F). 
da incompatibilidade associada à turbidez só é significativo quando avaliada a possibilidade de enquadramento na classe 1 .

\section{CONCLUSÕES}

Os parâmetros fósforo total e coliformes termotolerantes apresentaram elevados percentuais de incompatibilidade, independentemente da classe de uso, da perspectiva de enquadramento (comum ou diferenciado ao longo do rio) e do período do ano hidrológico (seco ou úmido). As eventuais alternativas de enquadramentos exigirão que, nos horizontes de planejamento estabelecidos por futuros planos de bacia, sejam estabelecidos esforços para uma substancial redução das concentrações de fósforo e coliformes termotolerantes nos corpos d'água da bacia hidrográfica do Rio Jucu.

A avaliação sazonal demostrou que apenas o parâmetro de turbidez, quando considerado o padrão de enquadramento classe 1, apresentou diferença entre as frequências de incompatibilidade observadas para os períodos seco e úmido do ano hidrológico. $\mathrm{O}$ aumento da frequência de incompatibilidade dos valores de turbidez observada para períodos chuvosos demonstra a necessidade de ações visando à proteção do solo contra a erosão. Para os demais parâmetros avaliados neste trabalho não foram observadas diferenças significativas nos resultados referentes aos diferentes períodos do ano hidrológico.

A variação espacial das frequências de incompatibilidade não indicou como razoável a definição de diferentes classes de enquadramentos ao longo do Rio Jucu, com eventual flexibilização das classes de uso de montante para jusante.

O aperfeiçoamento e a intensificação do monitoramento de qualidade da água no Rio Jucu, incluindo campanhas em períodos de cheias e secas acentuadas, permitiria o aperfeiçoamento das curvas de probabilidade ajustadas no presente estudo e, consequentemente, da análise relativa à definição de classes de enquadramento para trechos do Rio Jucu em função de incompatibilidades com os padrões de qualidade ambiental empregados como orientadores para o processo de enquadramento.

\section{REFERÊNCIAS}

ACHLEITNER, S.; TOFFOL, S.; ENGELHARD, C.; RAUCH, W. (2005) The European water framework directive: water quality classification and implications to engineering planning. Environmental Management, v. 35, n. 4, p. 517-525.

ANA - AGÊNCIA NACIONAL DE ÁGUAS. (2002) HIDRO.EXE: Sistema de Informações Hidrológicas. Versão 1.O. Brasília: ANA.

BINOTTO, D. (2012) Proposta de Enquadramento Para Bacia Hidrográfica do Arroio Jacutinga, Município de Ivorá - RS. Dissertação (Mestrado em Engenharia Civil e Ambiental) Universidade Federal de Santa Maria, Santa Maria.

BRASIL. (1997) Lei no 9.433, de 8 de janeiro de 1997. Institui a Política Nacional de Recursos Hídricos, cria o Sistema Nacional de Gerenciamento de Recursos Hídricos, regulamenta o inciso XIX do art. 21 da Constituição Federal, e altera o art. 10 da Lei no 8.001, de 13 de março de 1990, que modificou a Lei no 7.990, de 28 de dezembro de 1989. Diário Oficial da União, Brasília, DF, 9 jan. 1997. Seção 1, p. 470.

BRITES, A.P.Z. (2010) Enquadramento dos corpos de água através de metas progressivas: probabilidade de ocorrência e custos de despoluição hídrica. Tese (Doutorado em Engenharia) Universidade de São Paulo, São Paulo.

CALMON, A.P.S.; SOUZA, J.C.; REIS, J.A.T; MENDONÇA, A.S.F. (2014) Subsídios para o enquadramento dos cursos de água da bacia hidrográfica do rio Itapemirim considerando aportes de esgotos sanitários. Revista Brasileira de Recursos Hídricos, v. 19, n. 1, p. 255-270.

CARONE, M.T.; SIMONIELLO, T.; MANFREDA, S.; CARICATO, G. (2009) Watershed influence on fluvial ecosystems: an integrated methodology for river water quality management. Environmental Monitoring and Assessment, v. 152, n. 1-4, p. 327-342.

CHEN, C.H.; LIU, W.L.; LEU, H.G. (2006) Sustainable water quality management framework and a strategy planning system for a river basin. Environmental Management, v. 38, n. 6, p. 952-973.

CUNHA, D.G.F.; CALIJURI, M.C. (2010) Análise probabilística de ocorrência de incompatibilidade da qualidade da água com o enquadramento legal de sistemas aquáticos - estudo de caso do rio Pariquera-Açu (SP). Engenharia Sanitária e Ambiental, v. 15 n. 4 , p. 337-346.

CUNHA, D.G.F.; CALIJURI, M.C.; LAMPARELLI, M.C.; MENEGON JR, N (2013) Resolução CONAMA 357/2005: análise espacial e temporal de não conformidades em rios e reservatórios do estado de São Paulo de acordo com seus enquadramentos (2005-2009). Engenharia Sanitária e Ambiental, v. 18, n. 2, p. 159-168.

GARCIA, C.S.; LOPARDO, N.; ANDREOLI, C.V.; GONÇALVES, R.C. (2012) Instrumento de gestão de recursos hídricos no saneamento básico. In: PHILIPPI JR, A.; GALVÃO JR, A. (Eds.) Gestão do saneamento básico: abastecimento de água e esgotamento sanitário. Barueri: Manole. p. 436-462. 
GUIMARÃES, B.O. (2013) Análise probabilistica de incompatibilidade entre a qualidade da água de rios do estado do Espírito Santo e os padrões de enquadramento legal. Dissertação (Mestrado em Engenharia de Saúde Pública e Desenvolvimento Sustentável) Universidade Federal do Espírito Santo, Vitória.

LEEWESTEIN, J.M. (2000) Proposição de suporte metodológico para enquadramento de cursos de água. Dissertação (Mestrado em Tecnologia Ambiental e Recursos Hídricos) - Universidade de Brasília, Brasília.

LEVINE, D.M.; STEPHAN, D.; KREHBIEL, T.C.; BERENSON, M.L. (2005) Estatística: teoria e aplicações. Rio de Janeiro: Livros Técnicos e Científicos.
MARINATO, C.F. (2008) Integração entre a gestão de recursos hídricos e a gestão municipal urbana: estudo da inter-relação entre instrumentos de gestão. Dissertação (Mestrado em Ciências em Engenharia Ambiental) - Universidade Federal do Espírito Santo, Vitória.

SILVA, S.C.; RIBEIRO, M.M.R. (2006) Enquadramento dos corpos d'água e cobrança pelo uso da água na bacia do rio Pirapama - PE. Engenharia Sanitária e Ambiental, v. 11, n. 4, p. 371-379.

SOONG, T.T. (1986) Modelos probabilísticos em engenharia e ciências. Rio de Janeiro: Livros Técnicos e Científicos.

SPIEGEL, M.R. (1985) Estatística. São Paulo: McGraw-Hill do Brasil. 